\title{
Toward a Conceptual Framework for Integrating Enterprises Performance and Risk Management
}

\author{
Seja Abdali \\ Business Administration Department, Faculty of Administrative and Financial Sciences \\ Al-Ahliyya Amman University, Amman, Jordan \\ E-mail: seja.abdali@gmail.com \\ Mou'ath Hourani \\ Software Engineering Department, Faculty of Information Technology \\ Al-Ahliyya Amman University, Amman, Jordan \\ E-mail: mouath.hourani@ammanu.edu.jo \\ Aymen Abuerrub \\ Computer Information Systems Department, Faculty of Information Technology \\ Al-Ahliyya Amman University, Amman, Jordan \\ E-mail: ayman_abuerrub@yahoo.com \\ Qusai Shambour
}

Software Engineering Department, Faculty of Information Technology

Al-Ahliyya Amman University, Amman, Jordan

E-mail: q.shambour@ammanu.edu.jo

Received: Oct. 9 Accepted: October $31 \quad$ Published: October 31, 2013

doi:10.5296/jmr.v5i4.4395 ～URL: http://dx.doi.org/10.5296/jmr.v5i4.4395

\begin{abstract}
The aim of this paper is to demonstrate the integration between performance and risk management through the use of balanced scorecard performance measurement tool. Both performance and risk management in organization's evaluation have several benefits for the organization's activities and, if applied properly, it can help an organization to reach its anticipated objectives. This research consists of two parts. In the first part, we present a review of the recent theoretical literature related to 1 ) the concept of performance and risk
\end{abstract}




\section{Macrothink}

Journal of Management Research

ISSN 1941-899X

2013, Vol. 5, No. 4

management; 2) the BSC as both performance and strategic measurement tool; 3) the BSC as performance evaluation tool in higher education institutions; 4) the interaction between risk and performance management in the context of different applications. The second part proposes a framework aiming at continuously controlling the integration of performance and risk, and providing information flow and feedback for future resources utilization and planning.

Keywords: Performance measurement, Risk management, Balanced scorecard, Key performance indicators, Higher education. 


\section{Introduction}

Ever since the concept of business was established and presented the way we know it nowadays, the only way to measure performance in organizations is focusing on the traditional performance measurement that deals mainly with measuring performance in more tangible sense. To measure profit, loss and, liabilities the balance sheets and income statement are used. In fact, these measures provide managers and decision makers with only an insight view about the organization financial performance ignoring many other aspects that makes the difference between success and failure (Person, 2009). These financial measures were accepted in times where some critical factors still haven't been emerged yet. The new critical factors are affecting today's business one way or another; like the effectiveness of internal processes, the capabilities and skills of human resources, the level of innovation and growth that organizations attain due to research and innovation, and customer satisfaction that is very important these days considering the highly competitive environment and the rapidly changing business dynamics (David, 2010).

The concept of Balanced Scorecard (BSC) was presented by Robert S. Kaplan and David P. Norton, in their Harvard Business Review article "The Balance Scorecard - Measures that Drive Performance”, as performance measurement framework that consists of non-financial performance measures along with financial metrics to provide managers and executives a more "balanced" view of organizational performance (Kaplan \& Norton, 1992, 2004). These non-financial measures are used to evaluate and monitor performance of intangible dimensions in organizations.

It is known that organization is facing many external and internal challenges. Combining external threats and internal weaknesses together can put at risk the existence of the organization and harm its competitive situation. To manage and control these unfavorable challenges, organizations need a structured approach to face it, which is known as risk management (Hopkin, 2010). Risk management refers to a set of methods and processes used by organizations to control risks and catch opportunities to achieve the organizational objectives. Risk management also provides a framework for management to work properly, and it is conducted by identifying significant events relevant to the organization's objectives, assessing them in terms of likelihood of occurrence and impact if event occurs, selecting a response strategy, and monitoring them by identifying and proactively addressing risks and opportunities (Hopkin, 2010).

The main focal point of this paper is to link performance and risk management through the continuous evaluation of the organization performance statuses using the BSC as a measuring and evaluating performance tool. BSC should be simplified and clearly defined in organization's strategic based system, it aligns the work of people within the organization vision and strategy; communicate strategy, customer satisfaction with the technology used in one framework (Rohm, 2012). The main difference between BSC and other measurement tools is that regular tools are mainly financially focused while BSC covers the other areas that eventually affect the financial measures.

The aims of this paper are to: 
- Clarify the performance and risk management concepts and their applications.

- Explore the role of BSC as performance and strategic management tool.

- Demonstrate the using of BSC as performance evaluation tool in higher education.

- Explore the interaction between risk and performance management in the context of different applications.

- Develop a conceptual framework encapsulating the elements of risk and performance and demonstrate the interaction between these components. The framework aims to prevent and lessen the impact of risk and use resources effectively and efficiently.

The remainder of this paper is organized as follows: Section two briefly describes the research background and related works where the researchers present the latest regarding: 1) the concept of performance and risk management; 2) the BSC as both performance and strategic measurement tool for organization that have commitment to achieve their strategy; 3 ) the BSC as performance evaluation tool in higher education institutions specifically due to the importance of education in general and the competitiveness between universities to attract better investment and bigger market share; 4) the integration of performance and risk management, in general, in different kinds of organizations. In Section three, a framework that is explaining the mechanism of integration between performance and risk management is proposed. Also, in this Section, the authors suggest a framework that is applicable in organizations in general. The framework can be adapted by any organization according to its requirements and specifications. Finally, in Section four, we present the conclusions and proposals for future work.

\section{Background and Related Work}

\subsection{Performance and Risk Management Concepts}

Performance management was defined in many ways, and there is no single definition that is agreed-upon among the business specialists, Axson (2010) defines performance management as: "Business performance management encompasses all the processes, information, and systems used by managers to set strategy, develop plans, monitor execution, forecast performance, report results, and make decisions". Axson also sets a five-steps process that uses performance management to help organization to achieve its objectives: 1) identify improvement opportunity, 2) determine the priority of the opportunity, 3) investigate the causes of performance shortfall, 4) implement the changes needed in performance, and 5) maintain these changes. Another definition by Eckerson (2009) identifies performance management as "harnesses information technology to monitor the execution of business strategy and help organizations achieve their goals”. He considers performance management as a four-step process that involves strategy creation, planning, monitoring plans implementation, and finally adjusting organization's objectives and process to achieve strategic goals.

The BSC as a performance and most effective evaluation tool and provides organization with detailed performance information from four different critical perspectives areas. These areas 
are learning and growth, internal processes, customer satisfaction and financials perspectives. Some of these dimensions might be important for one organization other than the other, depending on its criteria and characteristics (Person, 2009). For example, pharmaceutical companies are focusing more on monitoring learning and growth dimension other than insurance or banking related organizations. The continuous monitoring of these four dimensions through the monitoring of the key performance indicators, that are belong to each one of the four dimensions, gives managers and decision makers a holistic idea about deviated and troubled sections that might cause risk of different kinds; financial ,operational or strategic (Person, 2009).

In this perspective, there are recent examples of use of performance management tools in different domains (Grigoroudis, Orfanoudaki, \& Zopounidis, 2012; Wu, 2012). In a study presented by Grigoroudis et al. (2012), a performance measurement system for public health care organisations, using the BSC methodology, is developed. The proposed system is very important as it is capable to describe the vision of the organization, to support individual departments, units, or employees in the achievement of common goals, and to focus on the most important improvement efforts. It does not focus on a single aspect of the organization (e.g. its finances), but rather contains the most important financial performance indicators, in addition to non-financial performance indicators that are able to examine the quality of the provided services, the satisfaction of internal and external customers and the ability of the organization to adapt and change. Thus, the system provides a balanced view of the organization and the benefits and risks of strategic and operational decisions. Another study presented by $\mathrm{Wu}$ (2012) aims to provide decision makers with a systematic approach for establishing a visual strategy map, taking into consideration the relationships between KPIs, to help organizations achieve their goals. It proposes a structural evaluation methodology to connect KPIs into a strategy map of the BSC for banking institutions. In this study, the most important evaluation indicators of banking performance, that are corresponding with the four BSC perspectives, are collected from the related literature and approved by a group of experts. Then, a multiple criteria analysis tool is used to find out the causal relationships between the KPIs and to set up a visualized strategy map with logical links to enhance banking performance. Thus, according to the established strategy map, management could better invest limited resources in the areas that need the most improvement. The research results demonstrate that the proposed approach is an objective and practical way to establish strategy maps more reasonably. Finally, the author confirms that the proposed framework can be a useful, applicable and valuable reference for other organizations in other industries.

Risk, as a concept, could be defined as an event with the ability to impact (inhibit, enhance or cause doubt about) the mission, strategy, projects, routine operations, objectives, core processes, key dependencies and/or the delivery of stakeholder expectations. In other word, risk is undesirable event that has an impact on different aspects of an organization, or has an impact on its survival to some extent. The main impact of risk in any organization is on organization's performances, and once the organization can control and take corrective action in troubled department, the risk potential will be mitigated, but not necessarily omitted or disappears. All organizations are operating with accepted percentage of risk, called 
acceptable risk or organization risk. In the situations, when risk exceeds that acceptable margin, it threatens organization strategy and operations, or even worse it could threaten the survival or existence of the organization (Hopkin, 2010).

The authors of the article (Gordona, Loeba, \& Tsengb, 2009) discuss the new trend in viewing the risk management. Instead of looking at risk management from a silo-based perspective, the authors noticed the new trend of holistic view of risk management which commonly referred to as Enterprise Risk Management (ERM). The primary objective of the paper is to examine the impact of ERM on the firm's performance. The authors argue that the ERM-firm performance relation is relying on several key firm-specific factors. The authors suggest five factors they believed to have an impact on the ERM-firm performance relation. These factors are: environmental uncertainty, industry competition, firm complexity, firm size, and board of directors' monitoring. The authors develop an ERM index, and claim to be the first to develop such an index. The theory was tested on 112 US firms that revealed the implementation of their ERM process within their annual reports the $10 \mathrm{~K}$ and the $10 \mathrm{Q}$ (A $10-\mathrm{K}$ Form is an annual report required by the U.S. Securities and Exchange Commission (SEC), which gives a comprehensive summary of a public company's performance). The findings support the theory presented in the paper confirming the basic argument that the firm should consider implementation of ERM system in conjunction with circumstantial variables surrounding the firm. The researchers conclude that the analyses suggest that their ERM Index (ERMI) is a reasonable measure of the effectiveness of ERM, taking into consideration the three limitations of their study; covering only the year 2005, using one-year excess stock market returns to measure firm performance, and the fact that there is no theoretical model describing which contingency variables should be considered in such studies.

A literature conducted by the authors in (Beasley, Chen, Nunez, \& Wright, 2006) identified the potential benefits of developing a set of Key Risk Indicators KRIs and the importance of their elements, and introduces an appropriate methodology for communicating KRI data to senior management. Since the main goal of developing a set of KRIs is to provide useful insights about potential risks that impact the achievement of the organization's objectives, the researchers think that the KRIs developing process must start with a firm grasp of organizational objectives and risk-related events that might affect the achievement of those objectives. Case studies of specific KRIs have been provided to help differentiate them from key performance indicators KPIs. The researchers notice the importance of the KPIs to the successful organization management by identifying underperforming aspects of the enterprise. Also they notice how senior management and boards can benefit from a set of KRIs that provide timely leading-indicator information about emerging risks. The researchers state that potential value of KRIs may be derived from different contributions such as risk appetite by determining an appropriate thresholds for action at different organization levels, risk and opportunity identification by designing KRIs to alert management to trends that may affect the achievement of organizational objectives or may indicate new opportunities, risk treatment by serving as triggering mechanisms for organizational units, as well as serving as controls by defining limits to certain actions, risk reporting by providing measurable data conducive to aggregation, and compliance efforts by demonstrating compliance with 
established requirements in areas such as capital adequacy or reserve levels. The researchers confirm that KRIs development can help in improving performance by reducing losses, identifying opportunities for strategic exploitation, and reducing the cost of capital, improving processes by reducing service disruptions and supply chain management, and enhancing customer experiences by avoiding unexpected decisions that may create risks, and finally KRIs development can help in improving workplace environment by reducing the episodes of crisis management which allow more stable and smoothly functioning organization.

London and Dewor (2009) present the global risk management survey of the risk management attitudes and capabilities that conducted by Accenture ${ }^{i}$ in 2009. The main objective of the survey is to find if companies are learning lessons of past failures to create new risk management processes, tools and training equal to the challenges ahead. The study include 250 of large enterprises, represented by their chief financial officers, chief risk officers and other risk executives. The major finding of the study was that current risk management capabilities are not equal to the challenges and that it is inadequately aligned with business strategy and poorly integrated into business operations. The survey also noticed a lack of integration of performance and risk management. The survey results also expected increasing in regulation as the costs of effective risk management are increasing. It shows that some companies are using outsourcing of parts of the risk management function to improve their efficiency, whereas other companies are investing more capitals in order to improve their risk management function. The survey is optimized of the ability of strong risk management to drive business performance. The study suggested four important keys to achieve high performance through improving risk management: developing integrated risk management capabilities, improving the information quality and the risk reporting frequency, risk-adjust the company's performance management processes, and increasing the involvement of the risk function in driving value creation. The survey considers risk management and performance management as two sides of a coin, so they need to be integrating together in order to higher economic returns, sustainable shareholder value and increased stakeholder confidence in spite of an uncertain global economy.

\section{BSC as Performance and Strategic Management System}

A BSC is defined by Kumari as a "framework that focuses on shareholder, customer, internal and learning requirements of a business in order to create a system of linked objectives, measures, targets and initiatives which collectively describe the strategy of an organization and how that strategy can be achieved” (Kumari, 2011). The BSC, when firstly developed, was meant not only to keep scores of its four perspectives, but also to be used as strategic planning and management system. It aligns an organization around its mission and vision not only in the sense of tangible assets but to gather all the efforts of its human resources, capabilities, competencies to undertake more efficient and effective internal processes that satisfy both its customers and shareholder, which will lead the organization to achieve its financial and strategic goal. So it can be believed that BSC is used to measure the organizational performance towards achieving the strategic objectives (Rohm, 2012). 
The structure of BSC includes some cause-effect relationship that is commonly known as "strategy map". Strategy maps within the BSC suggest that the softer indicators of each perspective; learning and growth, internal processes, and customer satisfaction, will explain the measures and indicators of the financial dimension(Kaplan \& Norton, 2004). For example, the more efficient internal processes are, the more customers are likely to be satisfied about the service they are receiving. In another word, efficient processes are the cause of higher rates of customer satisfaction. In addition, each dimension of the BSC has a set of measures that are called key performance indicators (KPIs), metrics are installed to measure how far performance is from achieving operational objectives, KPI's are defined as: “quantitative metric representing one or more goals or objectives”(Gleim \& Flesher., 2012).The quantified target of each KPI is set after conducting a benchmark, which is an analytical and comparison tool that reflects the competitive situation of an organization in relation with other organization. By looking to organization tough competitor's performance you can determine the organization's competitive situation and take actions based upon their situations and having a fresh vision about market emerging challenges (David, 2010). Conducting a benchmark will enable the organization to set a realistic but yet an ambitious target and the same time taking into account the capabilities and resources of the organization and the target they are aiming to achieve to sustain their competitive situation.

The BSC translates an organization's mission and strategy into set of performance measures that provide the framework for implementing its strategy. The BSC aims to direct, help manage and change in support of the longer-term strategy in order to manage performance. Also, it can be considered as a strategic performance management tool for measuring whether the smaller-scale operational activities of a company are allied with its larger-scale objectives in terms of vision and strategy. The innovation of the BSC compared to the traditional performance measurement tools can be described in three ways, as follows (Kumari, 2011):

- It considers the financial indices in addition to the non-financial ones in determining the corporate performance level.

- It is not just a performance measurement tool but is also a performance management system.

- It can be used as a strategic management system that will simplify and translate vision and strategy, communicate and connect strategic objectives and measures, plan and set targets with aligning strategic initiatives, improve strategic feedback and learning.

Kumari (2011) also assesses the using of BSC in improving the organization's performance and proves its effectiveness. He also presents the benefits of using the BSC in four perspectives; financial, customer, internal business processes, and learning and growth perspectives, with detailed examples in multiple organizations besides confirming the theory of BSC as a tool to translate the strategic objectives of an organization that clarifies vision and strategy and links plans to activities. Finally, he outlines that BSC has seven advantages, which are: 1) translating vision and strategy into action, 2) defining the strategic linkages to integrate performance across organizations, 3) communicating the objectives and measures to a business unit, 4) aligning the strategic initiatives to attain the goals, 5) aligning organization 
employees in order to support the strategy, 6) providing a performance compensation, and 7) providing a feedback to the senior management.

Moreover, the concept of BSC as both performance and strategic management tool was well explained in (Person, 2009). Person demonstrates how BSC could clarify strategy and translate it into tactical action plan. He also stresses the importance of using BSC across the organizational levels to enable better communications of plans and strategy as barriers between departments, which let departments to consternate and focus on one goal which is achieving the organizational objectives in conjunction of the business unit goals.

The founders of BSC (Kaplan \& Norton, 2004) present a many cases related to the implementation of BSC as strategic management tool in different organization of different criteria. Some of these cases belong to companies that have been called to the BSC Hall of Fame for their recognition as successes stories. The first case is the case of Fulton county schools, where it's believed that the scorecard has boosted the accountability reports among employees and raise partnerships with local businesses which improve the fund of some essential programs in the school. The BSC helped the school to fulfill its mission of educate student to be responsible citizens. The other case was about PLIVA, a leading drug company in central and Eastern Europe that faced a lot of difficulties after the communism collapses. The company had very limited market then, and it faced many problems that hinder the company vision of expanding globally. Five years after the adoption of automated BSC software the company was called to the BSC Hall of Fame. The CEO of company said:"the company employees were well aligned around the strategy of the organization due to the using of BSC, which gather all the efforts and skills in the organization to satisfy its mission of expansion and penetration of other markets". To sum up, many evidences were reviewed about BSC as strategic management tool and not only advanced reporting tool, it's an effective tool, if well structured, that can use all the tangible and align all the effort, skills resources and capabilities in the interest of accomplishing the strategic mission of an organization (Kaplan \& Norton, 2004).

\section{Using BSC as Performance Evaluation Tool in Higher Education}

Higher education around the world faces huge challenges and the demand for this level of education is rapidly growing. To meet the challenge of this demand, higher education systems are experiencing a process of diversification and transformation. In this situation, the forms of education governance are also in a era of transformation. Specifically, governments are inviting higher education institutions to develop their own institutional policies and strategic plans, and to be in a position to obviously show the results of these. For this reason, institutions are required to build their own management capacity and implement better-performing information systems and monitoring tools. Consequently, an indicator system (also known as a 'scorecard) for higher education appears to be a vital management and communication tool (Martin, Sauvageot, \& Tchatchoua, 2011).

A number of researchers have the perception that the BSC, which has demonstrated its suitability for profit-oriented organizations, may not be appropriate for the academic industry (Lawrence \& Sharma, 2002; Storey, 2002). Nevertheless, others (Al-Zwyalif, 2012; Daryush, 
Mehran, \& Heydar, 2008; Karathanos \& Karathanos, 2005; Kassahun, 2010; Nayeri, Mashhadi, \& Mohajeri, 2008; Nelson, 2006; Panagiotis, Pavlos, Vasiliki, \& Maria, 2010; Schobel \& Scholey, 2012; Tobgy \& Radwan, 2011; Umashankar \& Dutta, 2007; Yu, Hamid, Ijab, \& Soo, 2009) challenge the above statement and provide several examples indicating the applicability of the BSC in an educational environment and prove that BSC can assist educational institutions in improving the performance quality in a similar way to the business sector (Karpagam \& Suganthi, 2013). Even though, the adoption and use of BSC for measuring the performance of higher education institutions is relatively new with little research carried out (Al-Zwyalif, 2012; Grigoroudis, et al., 2012; Karathanos \& Karathanos, 2005; Kassahun, 2010; Yu, et al., 2009).

Karathanos and Karathanos (2005) illustrate how the concept of the BSC can be adapted by the Baldrige Education Criteria for Performance Excellence. They also identify significant differences and similarities between the BSC for business and the BSC for education. In addition, the authors show examples of the BSCs of three recipients of the Malcolm Baldrige National Quality Award in Education. The BSCs in the examples confirm that although they cover the same perspectives, the individual measures differ significantly, reflecting the unique missions of the three organizations. A case study presented by Nelson (2006) discusses the motives behind adopting BSC approach in measuring the performance of the University of Edinburgh -Scotland, and describes how the BSC is employed in the university. The case study defines the KPIs that are used for measuring the performance along with the strategic alignment of the institutional initiatives with the BSC targets. It also outlines some lessons learned from Edinburgh's experiences, and summarizes how the university is further developing its approach. Finally, the case study proves the importance and effectiveness of BSC in measuring the success of the university.

The paper presented by Umashankar and Dutta (2007) aims to look at the BSC concept and discuss in what way it should be applied to higher education institutions in India. A valuable model is proposed that can be adapted with proper modifications to the management of tertiary institutions of education (whether it be a university, affiliate college, autonomous institution or private educational institution) in India. The study found that the adaptation of BSC by Indian universities and other institutions of higher learning can be beneficial in terms of identifying and selecting areas that they need to urgently focus upon and designing appropriate strategies. Nayeri et al. (2008), employs a BSC strategic model to assess the strategic environment of Business higher education in Iran with the use of tools like questionnaire and checklist for Iranian top business schools. These schools are assessed in the strategic perspectives of the proposed BSC model, and their strategic positions are defined in comparison to each other. The results of this study can be used directly in strategic planning of all other Iranian business schools, and it can present a holistic perspective of higher education institution in Iran. In the same context, a paper published by Daryush et al. (2008) aims to study the application of BSC as a powerful performance management tool in universities and higher education institutes. It explores the most practical models for universities' performance enhancement, and proposes an improved BSC model to improve 
quality in higher education. Finally, the paper proposes an implementation guide for BSC implementation in an Iranian context.

In a pilot study carried out by $\mathrm{Yu}$ et al. (2009), an e-balanced scorecard (e-BSC) prototype has been developed and evaluated for its effectiveness on measuring the performance of and managing academic staffs in the higher education setting. The proposed e-BSC enables the academic staff to set targets (start of the year), monitor and track personal performance (year-round) and evaluate individual achievements (year-end), thereby promoting performance planning as well as endorse a balanced performance management and measurement at the faculty level. The results of the study indicate that the e-BSC has shown to be effective and suitable for academic staff performance management and measurement and could potentially be used for all levels of staff in a similar context. A paper presented by Panagiotis et al. (2010) discusses the prospective applicability of BSC in Hellenic Navy's education and training in order to motivate and maintain continuous improvement. The paper clarifies the processes, purposes, and limitations for designing and developing a BSC for Hellenic Navy education and training systems as part of its self-assessment by developing and reporting a complete set of measures that include both leading and lagging indicators of performance. A study conducted by Kassahun (2010) outlines an academic scorecard that can be used, as a strategic BSC framework, for measuring higher education institutional performance in Ethiopia. The proposed framework is not a universal prescription to be followed by all higher education institutions in Ethiopia but it must be adjusted to the vision and strategic direction of a specific institution in a given period of time.

In the study presented by Tobgy and Radwan (2011), a BSC methodology is proposed and used as an educational institution performance monitoring tool and an assessment system, to be used in universities and higher education institutes in Egypt. In the proposed methodology, the higher education institutions improvement is monitored through measuring the KPIs that are categorized into six perspectives. These perspectives are: 1) Educational and learning excellence; 2) Scientific research excellence; 3) Community participation, environment development, and stakeholders; 4) Human and material resources; 5) Financial resources; and 6) Institutional capacity and quality management. The proposed tool measures the performance of the institutions through all its major perspectives, and it is flexible in which it can be modified according to institution mission and strategic priorities. Al-Zwyalif (2012) study aims at identifying the Jordanian Private Universities awareness' of the importance of implementing the BSC in the performance evaluation. Also, the study explores the availability of the basic requirements (financial resources and essential staff) to implement the BSC in Jordanian Private Universities. The results of the study indicate that the private universities in Jordan realize the importance of the BSC as a strategic tool in evaluating their performance. The results also point up the availability of financial resources and essential staff that are required to implement the BSC in the Jordanian Private Universities. Schobel and Scholey (2012) demonstrate the use of a BSC within a higher education distance learning environment and highlights the importance of financial strategies for higher education at a time when most universities are focused on performance metrics associated with learning. The findings of this study state that higher education organizations with well-defined 
financial strategies that are linked to educational outcomes will be well positioned for success.

\section{Performance and Risk Management Integration}

Theoretically, the integration between performance and risk management enables organization to both monitor and evaluate the performance effectively through BSC and to prevent further unfavorable consequences resulted from uncertain performances. The literature reviewed in this area supports the quest of this paper which is studying the relation between continuous monitoring for performance to catch the early alarm and the effect of the early diagnose of troubled performance and the mitigation of risk potential on the other hand.

The authors in (Jun, Qiuzhen, \& Qingguo, 2011) study the possibility of developing integrative model to explore the moderating effects of uncertainty on the relationship between risk management and information system (IS) development projects performance. The model depends on the vendor's perspective, rather than the client's perspective. The authors test their proposed model using a survey-based method to collect data. The results of the model support the theory that uncertainty to process performance indicated that project planning and control makes a smaller contribution to performance of IS development when inherent uncertainty compromises a higher effect and impact on the IS projects. The study also indicates that enhancing planning and control will improve process performance for low risk projects, and enhancing user participation will improve product performance for high risk projects.

Leysen and Nuffel (2010) present what they called a new integrated risk and performance management framework, that can help in self evaluation, in line with integrated performance management (IPM). The proposed framework integrates risk analysis and management as well as change management within IPM, and it can be used to evaluate the formal and structural aspects of the organizational management system and to improve its plans. The researchers described the principles that underlie the integration of IPM and IRM. To achieve this, the proposed approach should be organization-wide that involve both internal and external stakeholders, and then the researchers align the objectives and risks horizontally and vertically in order to an integrated and coherent whole. The next step was interrelating objectives and organizational risks to ensure covering all important risks specially the critical risks. Finally, the researchers try to balance both the risk management resources and organizational objectives activities by defining risk management activities and resources in the light of operational activities, and by evaluating the risk effects the organization objectives. The researchers introduce a new integrated risk and performance management process-oriented model, where the components of this model represent the management activities and results.

Low and his colleges in (2013) study the influence of ERM on the Singaporean construction industry. They investigate the relationship between ERM and the performance of Singaporean contractors in order to identify the obstacles that hinder the implementation of ERM. The researchers conduct a questionnaire-based survey to test the awareness of Singaporean contractors of ERM concept, and to record the effect of ERM implementation on 
their performance. The researchers claim that the result of their survey shows that implementation of ERM had positive impact on at least 10 performance indicators. The result also shows that implementation of ERM facing many obstacles such as implementation time, the lack of experienced staff, and insufficient resources.

Roslan and Dahan noticed in their paper (2013) that ERM has become a new worldwide concept of holistically managing organizational risk. They argue that adopting ERM will improve organizations business performances. Although ERM has received a positive response from organizations around the world, they said that various studies show evidence that there are lacking in the practice of ERM among Malaysia organizations. Their research tries to find out the reason behind this lacking. They propose in their paper a new conceptual framework to investigate the mediating effect of ERM on organizational culture and business performance in Malaysian public sector companies. To achieve this objective the researchers examine the extent of ERM practices Malaysian public sector companies, and the relationship between risk culture and organizational performance. And then they investigate the mediating effect of ERM practices on risk culture and organizational performance. The researchers study the eight industries listed on the main board of Bursa Malaysia. They chose sample of 767 organizations consist of consumer products, construction, industrial products, infrastructure, plantations, properties, trading/services and technologies. They exclude the financial industry because of their different rules and approach of ERM. The researchers conclude their work that their proposed conceptual framework explains the significant relationship between risk culture and ERMand its affect on the organizational performance. They claim that adoption and implementation of ERM in Malaysian organizations are still in an early stage.

Palermo (2011) tries to link risk to performance management through top management reporting. The researcher examines how risk-related information are reported to senior managers, and how these information are linked to performance management. The researcher builds his research based on a large UK energy company which has more than 10000 employees and is divided into four Business Units. The researcher conclude from his work that the way in which risk is related to performance management is based on different elements that may inhibit or facilitate the integration of performance and risk management processes, such as the presence of a different periodicity of risk and performance reporting, or the presence of a clear cut strategy that serves as a reference point for both risk and performance targets. The researcher also concludes that performance management tools can help in providing risk information. For example performance reports can help the organization to develop an awareness of emergent issues by highlighting unexpectedly changing performances, also analyzing KPIs can gave a good understanding of whether the business is becoming more or less risky.

The Economist Intelligence Unit (2010) conducts an online survey of 177 executives from all over the world to determine their usage of performance and risk management in their organizations. The main problem the report tries to discuss is the centralized planning organization, and the relationship between the level and position of manager and his awareness of risks. The report claims that if the manager is closer to customers, markets and 
suppliers, the risks are more visible him. The report noticed that many managers accept "too optimistic" performance objectives because of top-level managers pressure, they said that top-level managers show little enthusiasm for considering risk when setting performance objectives, and that there is little perceived need in their organizations for the integration of risk and performance management because there is insufficient focus on risks faces their organizations. The survey respondents say that risks management are best integrated into the most threaten decisions, capital expenditure decisions (in all industries except financial), supply-chain performance (in energy and manufacturing), Product development goals (in technology industry), and long-term planning in technology and professional services. The report conclude that integrating performance and risk management where success in organizations that focusing firstly on process and how to gain executive support, then thinking about how activities can be automated. The last step is focusing on the areas with greatest payoff.

\section{The Proposed Framework: Higher Education Perspective}

This section first presents a description of the proposed framework. Then, we provide a list of the KPIs which have been chosen to be used in this research.

\subsection{Description of the proposed framework}

The risks that higher education sector endures might seem different than other sectors. Besides losing market share which is a common risk most organizations could face, there is another kind of risk that higher education sector is facing which is: the quality of the output, the students, that are might be unable to cope with the dynamic and demands of labor market. Another risk is hiring under qualified employees, both academics and administrators, which could harm the internal processes, researches and development, and eventually customer satisfaction which will lead to trouble and undesirable financial statuses.

The literature reviewed related to the education in general illustrates a number of successful examples of the applicability of BSC as a strategic and performance management tool and recommending it in managing educational institutions (refer to Section 2.3). Whereas most previous studies were revolving around the concept of using the BSC only as performance management tool in achieving the organizational strategic goals, the proposed framework advances the use of BSC performance evaluation tool by triggering the risk management model to start the risk identifying process. Accordingly, a conceptual framework is proposed that can be considered as first practical proposal in this line of research which concerning the integration of BSC and risk management. The benefit of such integration will be in the interest of achieving strategic goals and objectives besides keeping the risk within the acceptable limit of the organization itself. The proposed framework is applicable in all different sorts of organizations and will be tested on higher educational institutions due to the importance of this sector and to the researcher's academic field of specialty.

The proposed framework, as shown in Figure 1, is an integration of three subjects in the organization (Strategic planning (A), Performance management (B) and Risk management 
(C)) which happened to be separated. The effort of this research is to link these subjects in one theoretical framework that will be tested later in the future work.

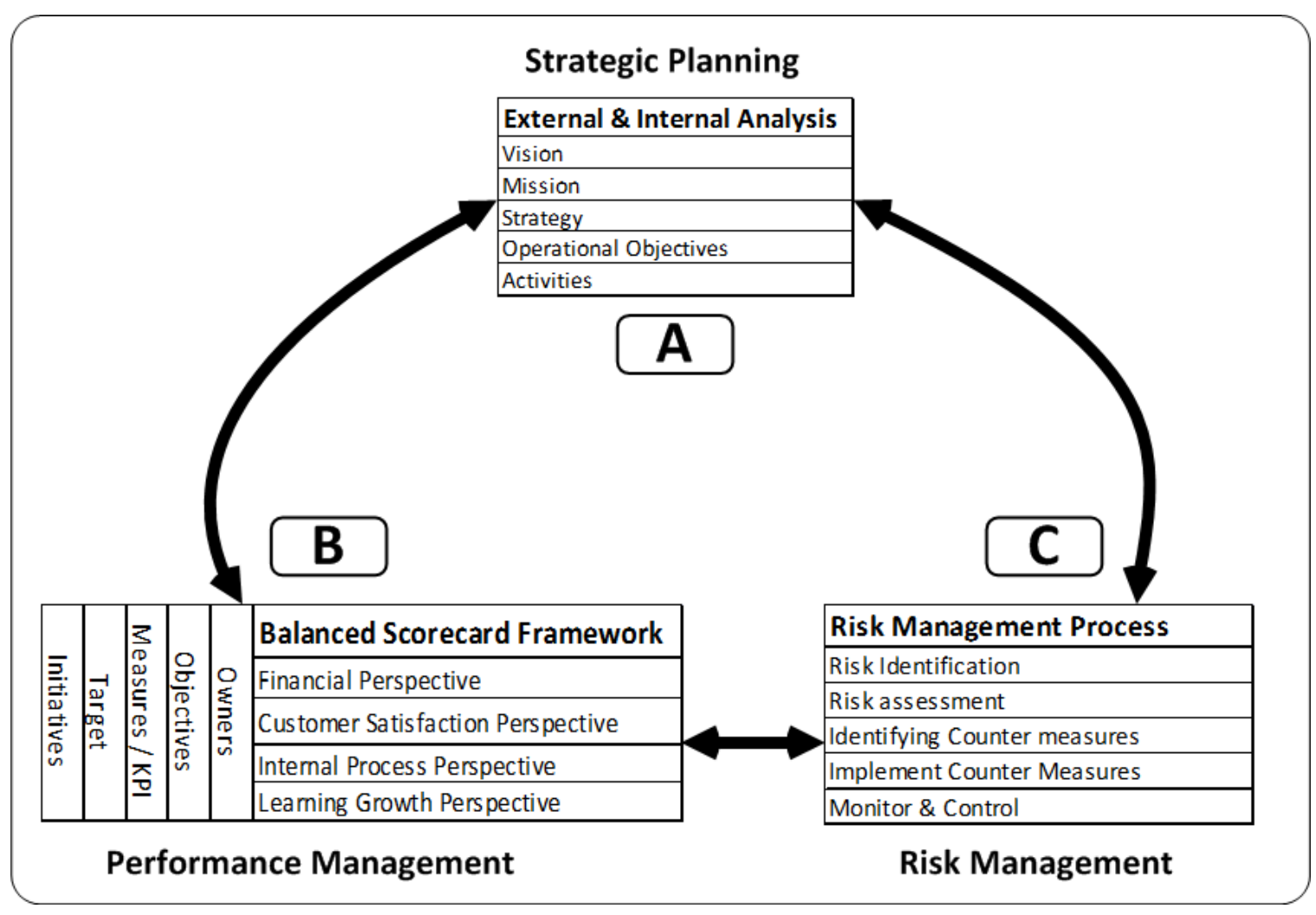

Figure 1. Proposed Framework

Looking at Figure 1, Strategic planning (A) starts with conducting the SWOT (Strengths, Weaknesses, Opportunities and Threats) analysis, then, the mission and vision are articulated. The mission is about visualizing an organization cause of existence, and the vision is the future picture of what an organization aims to be in the future. Setting the appropriate strategy should take into account the SWOT analysis results, mission and vision of the organization. The strategy will be then translated to a group of objectives that an organization aims to obtain. Any strategy even the best ones will stay inefficient until it is translated into a practical objectives. All resources and capabilities of the organization will be then devoted to achieve strategic goals and objectives. Objectives should be clear, realistic but yet ambitious, and stemmed directly from the organization's strategy (David, 2010).

Almost all businesses shared few common goals of survival, growth, increasing profit and market share. These general goals are translated to more detailed objectives. Each objective would be detailed and translated into activities that consist of lists of initiatives which can be considered as the input point to next section (B). The BSC represents the performance management of initiatives and activities in the organization. Performance of teams (owners) and managements is devoted to satisfy the targets of activities. The BSC will facilitate listing the details related to every activity by setting initiatives, objectives for each initiative, KPIs 
for measuring the performance of each initiative, setting target for each KPI, assigning teams to fulfill each activity (Kerzner, 2011).

In this paper, experts in higher education sector had carefully chosen a list of KPIs to be used in private universities to monitor the performance in the four dimensions of BSC. These dimensions are organized upon the concept of strategy map in which each dimension will be the root cause for effecting the other dimension. For example, the improper trained employee (a KPI in the financial dimension: Budget devoted for developing Human resources' skills) will sure lead to higher percentage of errors (a KPI in the internal processes dimension: On average, number of critical error in admission department), in other words the lowest the organization's budget for training the higher errors will be committed by the poor trained employee. Another example is the poor percentage of student's diversity (internal processes dimension) that reflects poor advertising for the university abroad which will eventually lead to lose market share for other universities that are leading better advertising and promotion practices. Setting target for your student's diversity should be compared with other universities in order to avoid negative growth. The sequence of indicators in BSC is designed to monitor the performance in the areas targeted by the indicators and to help take early corrective actions. In the previous example, the performance is under the desired limit in the area of advertising abroad which reflects troubled internal process that should be treated before it is transacted to a financial loss. Managers and team leaders should train team members to read statuses and make sure that this framework along with detailed BSC is communicated across the organization to avoid any misunderstanding and inaccurate reading of the BSC.

The continuous monitoring of KPIs provides the management and decision makers with a holistic image and reviews about the performance statuses in the four dimensions. Due to the strategy map within the structure of BSC monitoring; one dimension of BSC will give indication about the next dimension, for example learning and growth statuses will effect customers satisfaction, and so on. As a result, the financial dimension which is the most important for stakeholders is affected by all the other dimensions due to the consequence of strategy map within the scorecard.

Each organization has its own objectives and targets for their performance to be accomplished through the activities and initiatives of the organization, in case performance deviated from meeting those targets, the organization will have to mitigate the impact of the unfavorable event on the organization and its performance or even existence in extreme cases. The process and the efforts of reducing the impact of certain unfavorable event is risk management. Setting targets for each indicator is not a random procedure. Firstly, it must be initiated with paying attention to the capabilities and resources within the organization and the way it can seize opportunities and correct their weaknesses. Secondly, it must adopt the benchmark exercise with a superior organization in the same industry to avoid comparing the organization with itself only as this will lead to a negative growth when ignoring other organization's performances. Continuous monitoring and carful comparison for the target will give the organization the chance to act proactively before any further damage is happened. Section (C) of the framework will be activated once underperformed KPI is 
spotted. In this case, BSC can be described as video shooting for performance status in the organization, having the awareness and the knowledge about different sequences resulted from troubled areas will enable the teams and managers to catch early alarm of risk potential (risk identification). Only skilled and trained team members could catch early signs of trouble when reading a BSC. The continuous monitoring of BSC statuses by specialized teams can save the organization effort and budget devoted to mitigate the risk and make it within the risk appetite of the organization. Risk characteristics and impacts differentiate from one organization to another depending on their operations, industry, place and general environment. What is considered to be risky for one organization could be acceptable for another one. Every organization must list risk triggers that matter for their industry based on history or personal expertise trying to list the most probable ones in the industry of the organization.

To sum up, the proposed framework enables continuous monitoring of the performance through using the BSC (performance management) while reduces the impact of risk on the organization by identifying the underperformed areas in the BSC and consider them as risk potentials that need more attention and strict solution from managements (risk management). The risks identified will be analyzed further together with their impacts on the organization and appropriate actions required to mitigate each risk. Also, the risks identified will be registered and kept in the organization as a reference when setting the next strategic plan or setting targets for performances. Finally, the proposed framework will provide an effective an efficient means to utilize organization's resources.

\section{A list of KPIs used in this research}

After analyzing the literature in this field, a list of KPIs for each of the four perspectives have been selected as follows:

\section{Financial dimension}

1. University market share comparing with leading competitor

2. On average, academic and staff Salaries compared with benchmark universities or other appropriate competitors.

3. University budget includes allocation for strategic initiatives.

4. University budget devoted for technology.

5. Budget devoted for developing Human resources’ skills.

6. Percentage of regular student to scholarship and fellowship students.

7. Budget devoted to support services (data shows, labs, smart boards).

\section{Customer Satisfaction Dimension}

1. On average, student satisfaction about teaching and learning services provided by the university. 


\section{Macrothink}

Journal of Management Research

ISSN 1941-899X

2013, Vol. 5, No. 4

2. Percentage of students complains about administration procedures.

3. Speed of responding to student complains and grievances.

4. On average, numbers of trained experts and certified employees working in administrative positions

5. Time of wait for a student in admission department during registration.

6. Percentage error in admission department.

7. On average, student satisfaction of online services provides by university.

8. Budget devoted for improving service in admission department.

III. Internal processes perspective

1. Percentage of student diversity.

2. Average library usage by student.

3. Evaluation of advertising and promotion for university.

4. Evaluation of terms of accepting master students other than those required by ministry of higher education (such as personal interview, years of experience, letters of recommendations)

5. Percentage of students recruited out of Jordan.

6. Percentage material delivered electronically.

7. Percentage of electronic links for communication among departments of university.

IV. Learning and Growth perspective

1. Percentage faculty's full time instructors engaged in research.

2. Evaluation of Number of papers published by students.

3. Evaluation of publications in refereed journals in the previous year per full time faculty members.

4. Evaluation of budget devoted to support research and development.

5. Percentage of students per computer.

6. Evaluation of number of ideas put forward by individuals to team leaders.

7. Evaluation of number of patents received at local level.

8. Evaluation of number of patents received at international level.

9. Percentage of researchers moving from research and development to start up own business.

10. Evaluation of number of books published by full time professors. 


\section{Conclusions and Future Works}

This paper has demonstrated the integration between performance and risk management through the use of BSC performance measurement tool. Firstly, a comprehensive literature is provided describing the concept of performance and risk management; the BSC as both performance and strategic measurement tool for organization; the BSC as performance evaluation tool in higher education institutions; and the integration of performance and risk management in general in different kinds of organizations. Secondly, a conceptual framework that integrates the elements of performance and risk and express the interaction between these components is proposed. The framework aims to continuously control the integration of performance and risk, thus, preventing and lessening the impact of risk and providing information flow and feedback for future resources utilization and planning.

The importance of applying the integrated framework stands clearly in the following benefits: 1) the efficient allocation and deployment of resources to the various activities in the organization according to the statuses of performance indicators and risk feedback; 2) the effectiveness and efficiency of resources utilization will offer synergy to make up for the relative limited resources when compared to the requirements of every activity and initiative in the organization; and 3) the feedback stemmed from both performance statuses and risk identification will help organizations in any future planning for the issues related to the four perspectives of the BSC like budget devoted to an activity, human resources, technologies and equipment's to the initiatives in the BSC four dimensions.

In future work, we have chosen the higher education sector to apply the proposed framework. The choice of this specific sector in the Jordanian market is due to the fact that Jordan has a very promising criteria when it comes to education in which many Arab students prefer Jordan as the first choice when they have the option of studying abroad. The survey has been designed, approved and distributed and we are currently in the process of collecting the data. After that, we will analyze the results with the aim of setting standards for private universities in Jordan through testing how far they are from adopting the international benchmark. The closest university to the international benchmark will be named as the Jordanian benchmark university. Whenever the universities are under performed or troubled then the university will be considered as crossing risk appetite or facing a potential risk. Applying such framework in higher education institutions will standardize performance and minimize risk both financially and those related to the quality of universities output.

\section{References}

Al-Zwyalif, I. M. (2012). The Possibility of Implementing Balanced Scorecard in Jordanian Private Universities. International Business Research, 5(11), p113. http://dx.doi.org/10.5539/ibr.v5n11p113

Axson, D. A. (2010). Best practices in planning and performance management: radically rethinking management for a volatile world (Third ed.). New Jersey: John Wiley \& Sons.

Beasley, M., Chen, A., Nunez, K., \& Wright, L. (2006). Working Hand in Hand: Balanced Scorecards and Enterprise Risk Management. Strategic Finance, 87(9), 49-55. 
Daryush, F., Mehran, N., \& Heydar, M. (2008). Balanced Scorecard Application IN Universities And Higher Education Institutes: Implementation Guide In An Iranian Context. Annals of University of Bucharest, Economic and Administrative Series, 2, 31-45.

David, F. R. (2010). Strategic Management (Thirteen ed.): Pearson Press.

Eckerson, W. W. (2009). Performance Management Strategies: How to Create and Deploy Effective Metrics (pp. 1-36): The Data Warehousing Institute.

Economist Intelligence Unit. (2010). Integrating Risk and Performance Collaborating for Better Decisions and Greater Buy-in (pp. 1-17). UK: The Economist.

Gleim, I. N., \& Flesher., D. L. (2012). CMA Review Part2 Financial Decision Making: John Wiley \& Sons.

Gordona, L. A., Loeba, M. P., \& Tsengb, C.-Y. (2009). Enterprise risk management and firm performance: A contingency perspective. Journal of Accounting and Public Policy, 28(4), 301-327. http://dx.doi.org/10.1016/j.jaccpubpol.2009.06.006

Grigoroudis, E., Orfanoudaki, E., \& Zopounidis, C. (2012). Strategic performance measurement in a healthcare organisation: A multiple criteria approach based on balanced scorecard. Omega, 40(1), 104-119. http://dx.doi.org/10.1016/j.omega.2011.04.001

Hopkin, P. (2010). Fundamentals of Risk Management: Understanding Evaluating and Implementing Effective Risk Management: Kogan Page.

Jun, L., Qiuzhen, W., \& Qingguo, M. (2011). The effects of project uncertainty and risk management on IS development project performance: A vendor perspective. International Journal of Project Management, 29(7), 923-933. http://dx.doi.org/10.1016/j.ijproman.2010.11.002

Kaplan, R. S., \& Norton, D. P. (1992). The balanced scorecard: Measures that drive performance. Harvard Business Review, 1992(Jan-Feb), 71-79.

Kaplan, R. S., \& Norton, D. P. (2004). Strategy Maps: Converting Intangible Assets into Tangible Outcomes. Boston: Harvard Business School Press.

Karathanos, D., \& Karathanos, P. (2005). Applying the balanced scorecard to education. Journal of Education for Business, 80(4), 222-230. http://dx.doi.org/10.3200/JOEB.80.4.222-230

Karpagam, P. U., \& Suganthi, L. (2013). Performance measurement of organisations: a review of balanced scorecard technique. International Journal of Business Performance Management, 14(2), 129-148. http://dx.doi.org/10.1504/IJBPM.2013.052940

Kassahun, T. (2010). Rethinking institutional excellence in Ethiopia: adapting and adopting the balanced scorecard (BSC) model. Journal of Business and Administrative Studies, 2(1), 22-53. http://dx.doi.org/10.4314/jbas.v2i1.63517 
Kerzner, H. R. (2011). Project management metrics, KPIs, and dashboards: a guide to measuring and monitoring project performance (First ed.). New Jersey: John Wiley \& Sons.

Kumari, N. (2011). Balanced Scorecard for Superior Organizational Performance. European Journal of Business and Management, 5(2), 73-86.

Lawrence, S., \& Sharma, U. (2002). Commodification of education and academic labour-using the balanced scorecard in a university setting. Critical perspectives on accounting, 13(5), 661-677. http://dx.doi.org/10.1006/cpac.2002.0562

Leysen, J., \& Nuffel, L. V. (2010). A Framework for the evaluation of Integrated Risk and Performance Management. Paper presented at the Conference of the European Group of Public Administration Bern, Switzerland.

London, D., \& Dewor, E. (2009). Managing Risk for High Performance in Extraordinary Times. Outlook Point of View, 1.

Low, S. P., Liu, J. Y., Ng, S. H. M., \& Liu, X. (2013). Enterprise Risk Management and The Performance of Local Contractors in Singapore. The International Journal of Construction Management, 13(2), 27-41.

Martin, M., Sauvageot, C., \& Tchatchoua, B. (2011). Constructing an indicator system or scorecard for higher education: a practical guide. Paris: UNESCO IIEP.

Nayeri, M., Mashhadi, M., \& Mohajeri, K. (2008). Universities strategic evaluation using balanced scorecard. World Academy of Science, Engineering and Technology, 37, 332-337. http://dx.doi.org/10.1.1.192.8686

Nelson, D. B. (2006). Introducing the Balanced Scorecard in the University of Edinburgh. Retrieved from http://www.eua.be/eua/jsp/en/upload/Bruce\%20Nelson.1164021922470.pdf

Palermo, T. (2011). Integrating risk and performance in management reporting. CIMA Research Executive summary, 8(1), 1-6.

Panagiotis, S., Pavlos, S., Vasiliki, R., \& Maria, M. (2010). Applying Balanced Scorecard to Hellenic Navy's Education and Training: An initial approach. Global Journal of Health Science, 2(2), 192-197.

Person, R. (2009). Balanced Scorecard and operational Dashboards with Microsoft Excel (Second ed.). California: John Wiley \& Sons.

Rohm, H. (2012). Using the Balance Scorecard to Align Your Organization. Retrieved from http://www.accountingnet.ie/business_finance/Using_the_Balanced_Scorecard_to.php

Roslan, A., \& Dahan, H. M. (2013). Mediating Effect of Enterprise Risk Management Practices on Risk Culture and Organizational Performance. Paper presented at the The International Conference on Social Science Research (ICSSR 2013), Penang, Malaysia. 


\section{Macrothink}

Journal of Management Research

ISSN 1941-899X

2013, Vol. 5, No. 4

Schobel, K., \& Scholey, C. (2012). Balanced Scorecards in education: focusing on financial strategies. Measuring Business Excellence, 16(3), 17-28. http://dx.doi.org/10.1108/13683041211257385

Storey, A. (2002). Performance management in schools: could the balanced scorecard help? $\begin{array}{llll}\text { School Leadership } \quad \& \quad \text { Management, 22(3), } & \text { 321-338. }\end{array}$ http://dx.doi.org/10.1080/1363243022000020435

Tobgy, H. E., \& Radwan, M. M. (2011). Monitoring Egyptian Higher Education Institutions Performance Development, the Balanced Scorecard Approach Paper presented at the Quality Assurance in Higher Education: Challenges in the Arab Region, Abu Dhabi.

Umashankar, V., \& Dutta, K. (2007). Balanced scorecards in managing higher education institutions: an Indian perspective. International Journal of Educational Management, 21(1), 54-67. http://dx.doi.org/10.1108/09513540710716821

Wu, H.-Y. (2012). Constructing a strategy map for banking institutions with key performance indicators of the balanced scorecard. Evaluation and Program Planning, 35(3), 303-320. http://dx.doi.org/10.1016/j.evalprogplan.2011.11.009

Yu, M. L., Hamid, S., Ijab, M. T., \& Soo, H. P. (2009). The e-balanced scorecard (e-BSC) for measuring academic staff performance excellence. Higher Education, 57(6), 813-828. http://dx.doi.org/10.1007/s10734-009-9197-x

\footnotetext{
i Accenture is a global management consulting, technology services and outsourcing company, with approximately 266,000 people serving clients in more than 120 countries.
} 